\title{
Synthesis and Characterization of Boron Substituted Carbon Deposits on PFA-derived Carbon Substrates for Hydrogen Adsorption
}

\author{
Ali Qajar ${ }^{1}$, BillyPaul M. Holbrook ${ }^{2}$, Maryam Peer ${ }^{1}$, Ramakrishnan Rajagopalan ${ }^{3}$, Henry C. \\ Foley 1, 2, 3, 4 * \\ Michael Davis ${ }^{2}$, Karl T. Mueller ${ }^{2,5}$ \\ ${ }^{1}$ Department of Chemical Engineering, Pennsylvania State University, University Park, PA 16802 \\ ${ }^{2}$ Department of Chemistry, Pennsylvania State University, University Park, PA 16802 \\ ${ }^{3}$ Materials Research Institute, Pennsylvania State University, University Park, PA 16802 \\ ${ }^{4}$ Department of Chemical Engineering, University of Missouri System, University Hall, Columbia, MO 65211 \\ ${ }^{5}$ Environmental Molecular Sciences Laboratory, Pacific Northwest National Laboratory, Richland, WA 99352
}

Current Addresses:

Ali Qajar, Center for Petroleum and Geosystems Engineering, University of Texas at Austin, 200 E. Dean Keeton, C0304, TX 78712, US, (814) 4419481, ali.qajar@utexas.edu

BillyPaul M. Holbrook, MeadWestvaco, 5255 Virginia Avenue, N. Charleston, SC 29406, US, (484) 2017400,

billypaul.holbrook@mwv.com

Maryam Peer, Department of Chemical Engineering, Massachusetts Institute of Technology, MA 02142, US, (814)

865-9735, mpeer@mit.edu

Ramakrishnan Rajagopalan, 270 Materials Research Lab, Pennsylvania State University, PA 16802, US, (814) 8631880, rur12@psu.edu

Henry C. Foley, Department of Chemistry, University of Missouri, 309 University Hall, Columbia, MO 65211, US, (573) 882-6726, foleyh@umsystem.edu

Michael Davis, Bridgestone Americas Center for Research and Technology. 1655 South Main Street Akron, OH 44301, US, mdavis.nmr@gmail.com

Karl T. Mueller, Department of Chemistry, Pennsylvania State University, 002 Chemistry Building University Park, PA 16802, US, (814) 863-8674, ktm2@psu.edu

\footnotetext{
Abstract

The effect of boron substituted carbon $\left(\mathrm{BC}_{\mathrm{x}}, \mathrm{x} \sim 3-5\right)$ coatings on the hydrogen adsorption properties of porous carbons was investigated via spectroscopic characterization and hydrogen adsorption measurements. Thin films of $\mathrm{BC}_{\mathrm{x}}$ were synthesized by reacting $\mathrm{BCl}_{3}$ and * Corresponding Author. Tel: (573) 882-6726, Email: foleyh@umsystem.edu (Henry C. Foley) 
benzene in a chemical vapor and then depositing the product as a solid (CVD). The $\mathrm{BC}_{\mathrm{x}}$ deposits were collected on microporous carbon substrates and mesoporous silica aerogel. High-resolution solid-state boron NMR, ${ }^{11}$ B HR-NMR, detected boron atoms in a symmetric chemical environment with trigonal coplanar coordination. Results from analyses based on NMR, X-ray photoelectron spectroscopy (XPS), and d-spacings, calculated from electron diffraction and Xray diffraction (XRD) patterns, indicated that 17 at.\% boron was substitutionally incorporated into the carbon framework. Thus the material has an empirical formula of $\mathrm{BC}_{4.9}$. Hydrogen adsorption data were collected at 100 bar and $25{ }^{\circ} \mathrm{C}$. The $\mathrm{BC}_{\mathrm{x}}$ coatings reduced the surface area of the porous substrates by $30-50 \%$. However, at the same time, they increased the heat of adsorption and the adsorption capacities per unit area by as much as a factor of five. Diffuse reflectance infrared Fourier transform spectroscopy (DRIFTs) revealed wagging energies at 1190 $\mathrm{cm}^{-1}$ attributable to hydrogen interactions with C-B-C bonds.

\section{Introduction}

Solid-state gas adsorption is considered one of the most viable approaches to the storage of hydrogen for mobile fuel cell technologies. Carbons and metal organic frameworks (MOFs) are the two classes of adsorbents that appear to be the most promising candidates for hydrogen storage at present. There have been notable improvements in the hydrogen adsorption capacities of these adsorbents at cryogenic temperatures. Yet, there is still a large gap between their hydrogen storage capacities at ambient temperature and the DOE targets for on-board hydrogen storage systems for light-duty vehicles at room temperature [1]. Carbons possess superior physical properties and have high thermal and mechanical stability. These properties and their ready availability make them good candidates for large-scale storage media and applications. 
However, in contrast to the newer MOFs, carbons show low adsorption affinity for hydrogen. Microporous carbons typically provide heats of adsorption in the range of 6-9 $\mathrm{kJ} / \mathrm{mol}$. These fall well below the calculated ideal enthalpy of $15-20 \mathrm{~kJ} / \mathrm{mol}$, the so-called storage "sweet spot" in the energetics of interaction $[2,3]$. The "sweet spot" enthalpy must arise from forces that are stronger than those typical of physisorption. On the other hand, in this range, the heat of adsorption is below that which would arise from chemical bonding forces. Such forces would require the input of too much energy to release the hydrogen at ambient conditions. Therefore, the challenge for carbon science is to alter compositions in order to alter the surface chemistry sufficiently to provide for reversible high capacity hydrogen adsorption at ambient conditions.

Previous studies indicate that the incorporation of boron into a hexagonal carbon lattice enhances the surface affinity for hydrogen [4-12]. Substituted boron in carbon, referred to as $\mathrm{BC}_{\mathrm{x}}$, acts as an electron acceptor and provides a hole-carrier in the valance band that enhances electrical conductivity of the material. Previous studies show that $\mathrm{BC}_{\mathrm{x}}$ forms a graphite-like structure, even with as much as 25 at\% boron substituted into the carbon framework $[13,14]$. The extent of boron substitution depends on the synthesis conditions, the temperature and chemistry of reactants [15-20]. Different methods have been used to insert boron atoms into a carbon framework. In early work, Lowell demonstrated the formation of $\mathrm{BC}_{\mathrm{x}}$ by heating graphite flakes together with $\mathrm{B}_{4} \mathrm{C}$ at $2350{ }^{\circ} \mathrm{C}$. Due to the kinetic barrier to incorporation at this temperature, the procedure yielded only 2.35 at.\% boron in the graphite [21]. Chung and coworkers recently synthesized porous $\mathrm{BC}_{\mathrm{x}}$ derived from boron-rich polymer precursors $[9,10]$. Their $\mathrm{BC}_{\mathrm{x}}$ samples possessed $>7$ at. $\%$ boron and surface areas of as much as $780 \mathrm{~m}^{2} / \mathrm{g}$. In addition, at room temperature and 60 bar pressure, 0.62 wt. \% hydrogen was stored by the 
adsorbent. Chung's material had an initial heat of adsorption of $12.47 \mathrm{~kJ} / \mathrm{mol}$ and an average heat of adsorption on $11.5 \mathrm{~kJ} / \mathrm{mol}$.

Chemical vapor deposition (CVD) is another way to incorporate substantial amounts of boron into the carbon lattice [21-35]. Thrower and coworkers, and later Pantano and coworkers synthesized and studied physical properties of $\mathrm{BC}_{\mathrm{x}}$ films. In particular, they studied antioxidation effects of $\mathrm{BC}_{\mathrm{x}}$ coatings on carbon fibers [22-28]. The reactions were typically carried out at temperatures above $700{ }^{\circ} \mathrm{C}$ with a reactant mixture composed of a carbon precursor (e.g. $\mathrm{C}_{2} \mathrm{H}_{2}, \mathrm{C}_{6} \mathrm{H}_{6}$, etc.) and a boron precursor (e.g. $\mathrm{BCl}_{3}$ ) diluted by an inert gas (e.g. He, Ar). In this way, boron could be substituted into the carbon framework at levels up to $~ 17$ at.\%, beyond which the excess boron was intercalated or inserted into interstitial sites (steps and edges). The structure of $\mathrm{BC}_{\mathrm{x}}$ was very similar to that of graphite; it was nonporous and had an interlayer spacing of $\sim 0.34 \mathrm{~nm}[4,5,13,22]$.

Here we have adopted a synthesis procedure with benzene as the carbon source and $\mathrm{BCl}_{3}$ as the boron source to prepare $\mathrm{BC}_{\mathrm{x}}$ to be characterized and tested for hydrogen adsorption. This work integrates results from XPS, XRD, TEM and solid-state ${ }^{11}$ B MAS High Resolution-NMR spectroscopy. The use of solid-state NMR has yet to be fully exploited to examine the boron configuration in $\mathrm{BC}_{\mathrm{x}}$. Here we utilized $21 \mathrm{~T}$ magnet for solid-state ${ }^{11} \mathrm{~B}$ MAS HR-NMR studies to provide sufficiently high resolution to resolve the trigonal peak from the tetrahedral peak of B and with great accuracy. Secondly, since $\mathrm{BC}_{\mathrm{x}}$ has low porosity and could not be used directly as a hydrogen adsorption medium, high porosity $\mathrm{BC}_{\mathrm{x}}$ were prepared by depositing $\mathrm{BC}_{\mathrm{x}}$ on porous carbon substrates with high surface area. 


\section{Experimental}

\subsection{Materials and Synthesis}

All chemical reagents were obtained from Sigma Aldrich. UHP Ar, $\mathrm{He}$ and $\mathrm{H}_{2}$ were obtained from GTS-Welco. Benzene (99\%) was purged with UHP Ar for $1 \mathrm{hr}$ before use. Other chemicals were used as received without further purification. UHP He was used as the carrier gas in all experiments. $\mathrm{BC}_{\mathrm{x}}$ coatings were prepared via chemical vapor deposition by reaction between benzene and $\mathrm{BCl}_{3}$. Figure 1 shows schematic of the reactor. In a typical experiment, the carrier gas, He, bubbled through the benzene while the benzene source was kept at $25^{\circ} \mathrm{C}$. The benzene mass flow rate was calculated using the vapor pressure of benzene at room temperature. Due to the low vapor pressure of the reactants, the tubing, through which the reactants flowed, was wrapped with heating tape to prevent condensation. The reaction was carried out in a Lindberg horizontal tube furnace with a single heating zone of $1 \mathrm{ft}$ length and 2 inch diameter. Prior to each synthesis experiment, the quartz tubular reactor was cleaned by heating to the reaction temperature and holding at that temperature for 2 hours under flowing He. After that the reactant mixtures were introduced into the reactor at their designated flow rates. The reaction resulted in a solid product that covered the inner wall of the reactor as the gaseous byproducts, primarily $\mathrm{HCl}$, that exited the tube. The gaseous byproducts passed through a soda lime solution before being releasing into the hood system. The $\mathrm{BC}_{\mathrm{x}}$ solids were collected either as flakes or as deposits on porous substrates. The flakes were collected on an empty quartz boat placed at the center of the heating zone. To collect the deposits on porous substrates, first the porous substrates were outgassed and pretreated under vacuum at $90{ }^{\circ} \mathrm{C}$ for 6 hours. Then $200 \mathrm{mg}$ of freshly pretreated porous substrate was transferred into a quartz boat and placed in the reactor. After reaction had been completed, the reactor was cooled to room temperature over a three hour 
period. The typical flow rates of the reactants and operating conditions of the reactions are listed in Table 1.

Table 1: Typical reaction operating condition

\begin{tabular}{|l|l|}
\hline Temperature $\left({ }^{\circ} \mathrm{C}\right)$ & 900 \\
\hline Duration $(\mathrm{min})$ & $\leq 60$ \\
\hline $\mathrm{BCl}_{3}$ flowrate $(\mathrm{ml} / \mathrm{min})$ & 24 \\
\hline Benzene $(\mathrm{ml} / \mathrm{min})$ & 14 \\
\hline
\end{tabular}

Two microporous carbons were used as the porous substrates for the hydrogen adsorption study. Both carbons were derived from polyfurfuryl alcohol (PFA). The first carbon was synthesized by mixing polyfurfuryl alcohol and polyethylene glycol (PEG) into blends [36, 37]. For this synthesis, $0.05 \mathrm{~g} \mathrm{p}$-TSA was dissolved in $5 \mathrm{cc}$ THF at $10{ }^{\circ} \mathrm{C}$. Then $5 \mathrm{cc}$ of furfuryl alcohol (FA) was added to the THF solution and the mixture was capped and left stirring at $10{ }^{\circ} \mathrm{C}$ for 2 days. The PFA was mixed with PEG (MW=600) at volume ratio of $1: 1$ at $60{ }^{\circ} \mathrm{C}$ for $1 \mathrm{hr}$. Then the polymer blend was carbonized under flowing Ar with a $2 \mathrm{hr}$ ramp from room temperature to $800{ }^{\circ} \mathrm{C}$ followed by a $6 \mathrm{hr}$ thermal soak at $800{ }^{\circ} \mathrm{C}$. The carbon was crushed and sieved down to 38 micron. The carbon was further activated using $\mathrm{CO}_{2}$ oxidation at $900{ }^{\circ} \mathrm{C}$ [37, 38]. This sieved carbon powder was placed in the tube furnace under flowing Ar (at flow rate $1000 \mathrm{ml} / \mathrm{min}$ ) and the temperature was increased from room temperature to $900{ }^{\circ} \mathrm{C}$ in an hour. The carbon was left under flowing Ar for one more hour at $900{ }^{\circ} \mathrm{C}$, then the gas was switched to $\mathrm{CO}_{2}$ while the flow rate was kept constant. The carbon was oxidized until $40 \%$ of its initial mass was burned off. This oxidized, or "activated" carbon was labeled as AC.

The second carbon was synthesized via emulsion polymerization of furfuryl alcohol as described in reference [39]. Briefly, furfuryl alcohol was polymerized in a water-EtOH solution and in the presence of a surfactant, F-127, at room temperature. In this preparation, $\mathrm{HCl}$ was 
used as the acid catalyst. Emulsion polymerization resulted in the formation of polymer nanospheres (of submicron size). Adding concentrated sulfuric acid followed by heating the solution to $90{ }^{\circ} \mathrm{C}$ then solidified the polymer nanospheres. The heat treatment formed a highly viscous polymer solution. The polymer nanospheres were then washed with DI water and pyrolyzed to from carbon nanospheres. By adjusting the concentration of monomer and surfactant, the size of the nanospheres could be controlled in the range from $40 \mathrm{~nm}$ to 2 microns. This carbon is referred to as CS. This carbon was completely microporous with mean pore size of $0.5 \mathrm{~nm}$ and mean particle diameter of $500 \mathrm{~nm}$.

The $\mathrm{BC}_{\mathrm{x}}$ depositions on carbons were done with reaction times between 5 minutes and 1 hr. The samples were named as X-B-T, with X name of the substrate (either AC or CS), B an indicator of boron treatment and $\mathrm{T}$ as the reaction time in minutes (e.g. AC-B-10).

For comparison, the $\mathrm{BC}_{\mathrm{x}}$ were deposited on mesoporous silica aerogel and ${ }^{11} \mathrm{~B} \mathrm{NMR}$ spectra of these samples were also obtained. Since the synthesis was conducted at $900{ }^{\circ} \mathrm{C}$, it was important to determine if, and when, the pores began to collapse in the silica aerogel. The aerogel samples were heated for different times up to 60 minutes to determine the stability of the pore structure at $900{ }^{\circ} \mathrm{C}$. Measurement of the $\mathrm{N}_{2}$ BET surface area of silica aerogel showed that the initial surface area of silica aerogel $\left(733 \mathrm{~m}^{2} / \mathrm{g}\right)$ after 15,30 and 60 minutes of treatment at $900{ }^{\circ} \mathrm{C}$, was reduced to 465,201 and $93 \mathrm{~m}^{2} / \mathrm{g}$, respectively. The $\mathrm{BC}_{\mathrm{x}}$-coated silica aerogel were synthesized at conditions that were as similar as possible to those used to coat the porous carbons with one difference. In order to preserve the structure of the silica aerogel substrate for the $\mathrm{BC}_{\mathrm{x}}$ coating procedure, the silica aerogel was inserted into the heating zone right before starting the coating process. The sample was coated with $\mathrm{BC}_{\mathrm{x}}$ for 30 minutes. This is how the material examined for ${ }^{11} \mathrm{~B}$ NMR study was prepared. 


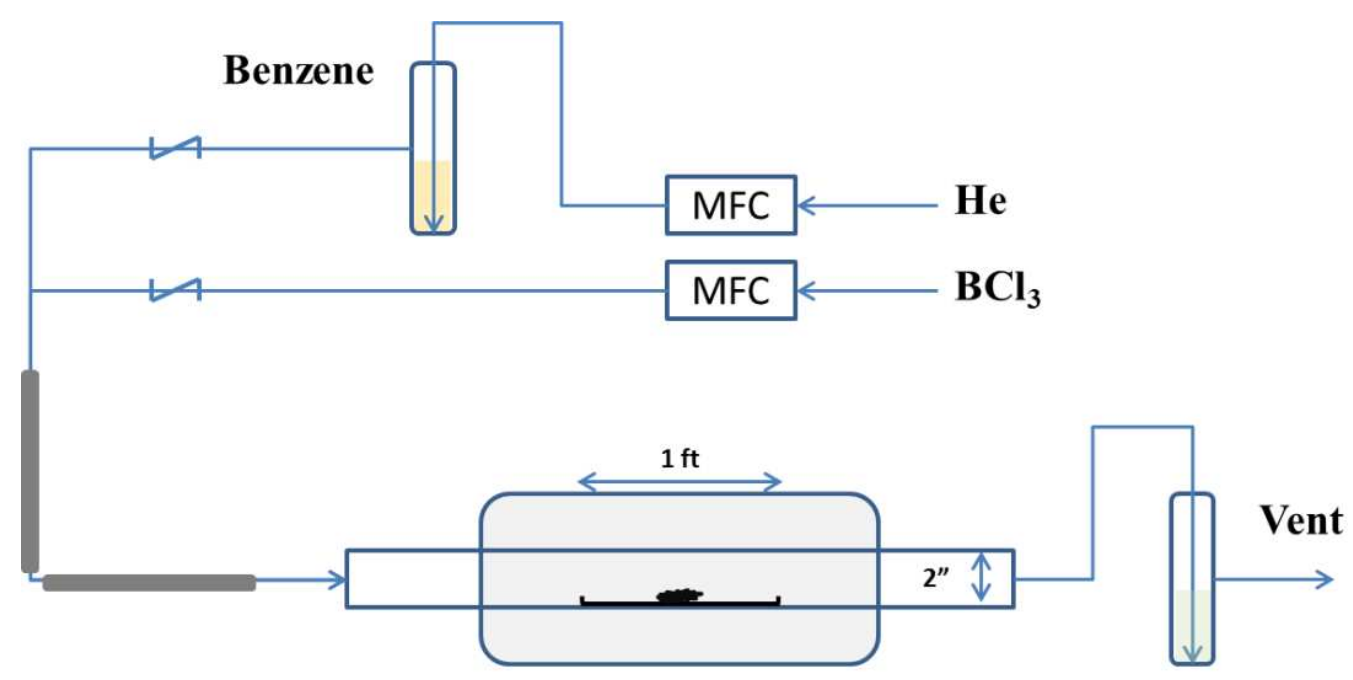

Preheater

Reactor

Soda lime

Figure 1: Schematic of the reactor for the synthesis of $\mathrm{BC}_{\mathrm{x}}$ deposits. Benzene and $\mathrm{BCl}_{3}$ were the reactants where benzene vapor was carried into the reactor by helium gas. The reactants were preheated to $50{ }^{\circ} \mathrm{C}$ before entering the reactor at atmospheric pressure. The $\mathrm{HCl}$ in the effluent was neutralized using soda lime solution. Long tubing at the exit was used to reduce temperature of the effluent gasses before they reached the soda lime.

\subsection{Characterization}

X-ray photoelectron spectroscopy (XPS) was performed on a Kratos Axis Ultra instrument with a monochromatic $\mathrm{Al} \mathrm{K} \alpha$ source and with a pass energy of $80 \mathrm{eV}$ for survey spectra and 40 and $20 \mathrm{eV}$ for high resolution spectra. Data were collected with a photoelectron take-off angle of $90^{\circ}$ from the surface.

X-ray diffraction patterns were collected using a Scintag PADV theta-2-theta Powder Diffractometer using non-monochromatized $\mathrm{Cu} \mathrm{K} \alpha$ radiation source with a step size of $0.02^{\circ} 2 \theta$ and a count time of $0.5 \mathrm{sec}$. Acquisition conditions were $35 \mathrm{kV}$ and 30mA. An NIST SRm 640c silicon standard was used to correct the line position and broadening of the carbon patterns. The Bragg equation was utilized to calculate the d-spacing of the boron-carbon material $\left(\mathrm{d}_{002}\right)$. 
Average crystallite sizes in the c-direction $\left(\mathrm{L}_{\mathrm{c}}\right)$, which is perpendicular to the layer planes, were calculated by the Scherrer equation.

Raman spectra were recorded using a confocal Raman microscope spectrometer (Renishaw inVia microRaman) set for $1 \mu \mathrm{m}$ spot sizes, with excitation from a $35 \mathrm{~mW}$ HeNe laser $(514 \mathrm{~nm})$ and optics set for $12 \mathrm{~mW}$, so that the sample spectra were recorded at $2 \mathrm{~cm}^{-1}$ resolution. The microcrystalline planar size $\left(\mathrm{L}_{\mathrm{a}}\right)$ was calculated from the ratio of intensities of the D-peak to the G-peak (ID/IG).

Solid state ${ }^{11}$ B MAS NMR Bloch decay experiments were conducted on a Varian Inova spectrometer interfaced to a home-built $3.2 \mathrm{~mm}$ magic-angle spinning (MAS) probe operating at a magnetic field strength of $21.1 \mathrm{~T}$ (observation frequency of $288.9607362 \mathrm{MHz}$ for ${ }^{11} \mathrm{~B}$ ). A short pulse $(\pi / 10)$ was used at radio frequency strength of $100 \mathrm{kHz}$ so that quantitative information could be obtained, and a frequency region of $200 \mathrm{kHz}$ was sampled. For processing, an exponential filter of $200 \mathrm{~Hz}$ was applied to the time domain data and the data set was zerofilled to 4096 complex data points before being Fourier transformed.

Transmission electron micrographs (TEM) were done on a Hitachi HF2000 High Resolution Transmission Electron Microscopy instrument.

TGA-air profiles were collected with $20 \mathrm{mg}$ of sample and at a gas flow of $100 \mathrm{ml} / \mathrm{min}$ and a temperature ramp of $10^{\circ} \mathrm{C} / \mathrm{min}$.

Diffusive reflectance infrared transmission spectroscopy (DRIFTS) data were collected on an IFS 66/S high-performance research grade FT-IR spectrometer in a Harrick Praying Mantis reaction cell. In these experiments, the powder samples were mounted inside the airtight sample cell and were treated under flowing argon at atmospheric pressure up to a temperature of 
$240{ }^{\circ} \mathrm{C}$. The sample was dosed with $5 \%$ hydrogen gas at room temperature and 7 bar pressure to study surface interactions between hydrogen and $\mathrm{BC}_{\mathrm{x}}$.

High-pressure adsorption data were collected on a custom-made, differential pressure adsorption instrument [40]. Prior to each adsorption experiment, the sample was heated to $250{ }^{\circ} \mathrm{C}$ overnight and under dynamic vacuum at 0.01 Torr. The hydrogen adsorption measurements were collected at $25{ }^{\circ} \mathrm{C}$ and up to 100 bar pressure. High-pressure data were fitted to the Freundlich isotherm model. Isosteric heat of adsorption profiles were calculated from the following equation $\Delta H_{\text {iso }}=-R\left(\frac{\partial \operatorname{Ln} P}{\partial(1 / T)}\right)_{n}$

where $n$ is the adsorption uptake in $\mathrm{mmol} / \mathrm{g}, \mathrm{P}$ is pressure in bar; $\mathrm{T}$ is the temperature in Kelvin and $\mathrm{R}$ is the universal gas constant.

Textural properties of the samples were measured by $\mathrm{N}_{2}$ and $\mathrm{CH}_{3} \mathrm{Cl}$ adsorption. $\mathrm{N}_{2}$ adsorption was conducted at $-196{ }^{\circ} \mathrm{C}$ using a Micromeritics ASAP2020 adsorption instrument. Before measurements, the samples were outgassed overnight under dynamic vacuum of 0.01 Torr at $200{ }^{\circ} \mathrm{C}$. Total pore volume of the samples were determined from $\mathrm{N}_{2}$ adsorption uptake at $\mathrm{P} / \mathrm{P}_{0}=0.97$. Micropore volume and external surface area of the samples were calculated using $\mathrm{t}-$ plot method. Mesopore volume was determined by subtracting micropore volume from total pore volume. Pore size distributions of the samples were determined by $\mathrm{CH}_{3} \mathrm{Cl}$ adsorption between 24 and $30{ }^{\circ} \mathrm{C}$ and below atmospheric pressure. Horvath-Kawazoe (HK) and BJH models were used to determine micropore and mesopore size distributions [37]. 


\section{Results and discussion}

\subsection{Results for Characterization of $\mathrm{BC}_{\mathrm{x}}$ films}

The XRD pattern of the as-deposited product is shown in Figure 2a. The peak at $2 \theta$ angle of $26.5^{\circ}$ is attributed to the $\mathrm{d}_{002}$ spacing between planes of the graphitic structure. The full width half max (FWHM) of the peak is inversely proportional to the crystallite size of the graphitic carbon sample in the $\mathrm{L}_{\mathrm{c}}$ direction. Broadness of the peak is indicative of turbostratic carbon, which corresponds to only short-range order [29, 41]. No long-range order is observed in the carbon sheets. For the peak observed at $26.5^{\circ}$ in Figure $2 \mathrm{a}$, the $\mathrm{d}_{002}$ spacing was calculated to be $0.344 \mathrm{~nm}$ and the $\mathrm{L}_{\mathrm{c}}$ was determined to be $3.6 \mathrm{~nm}$. A linear inverse relationship between boron content and the FWHM was reported earlier [33]. As the boron concentration increased the FWHM decreased. This was attributed to boron catalyzing the graphitization of the $\mathrm{BC}_{\mathrm{x}}$ structure.

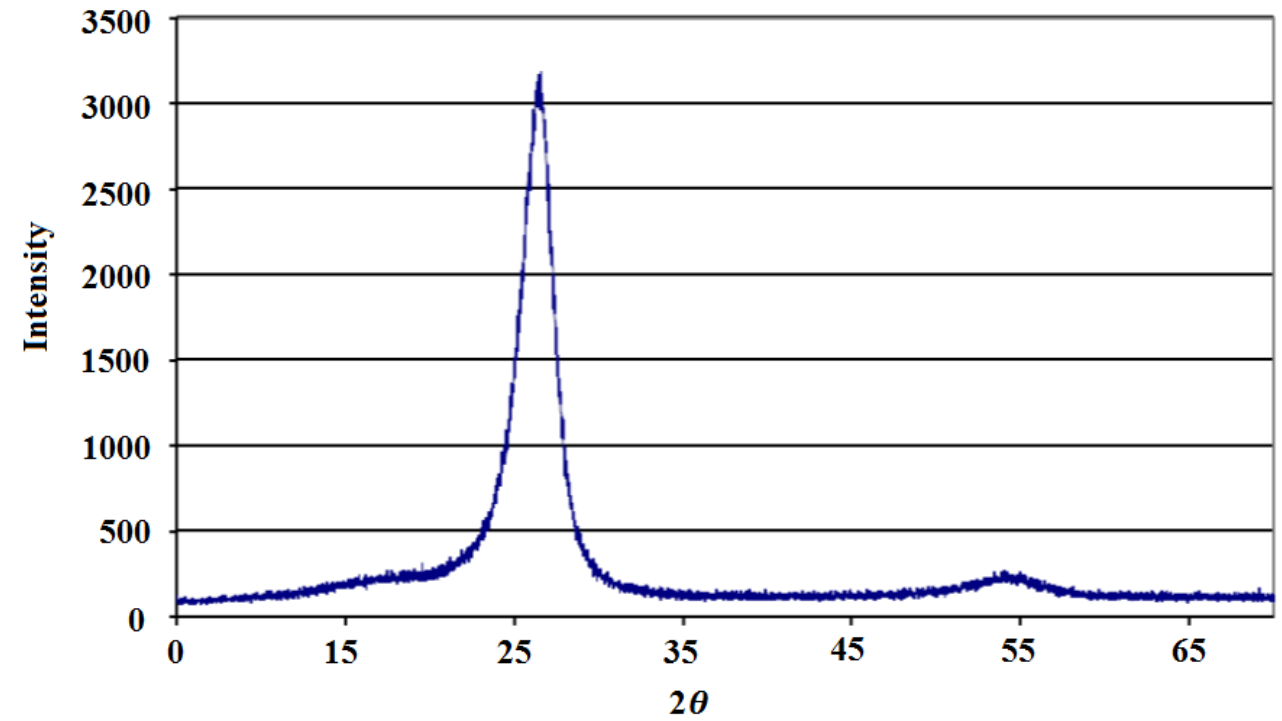

Figure 2a: XRD pattern of $\mathrm{BC}_{\mathrm{x}}$ films 


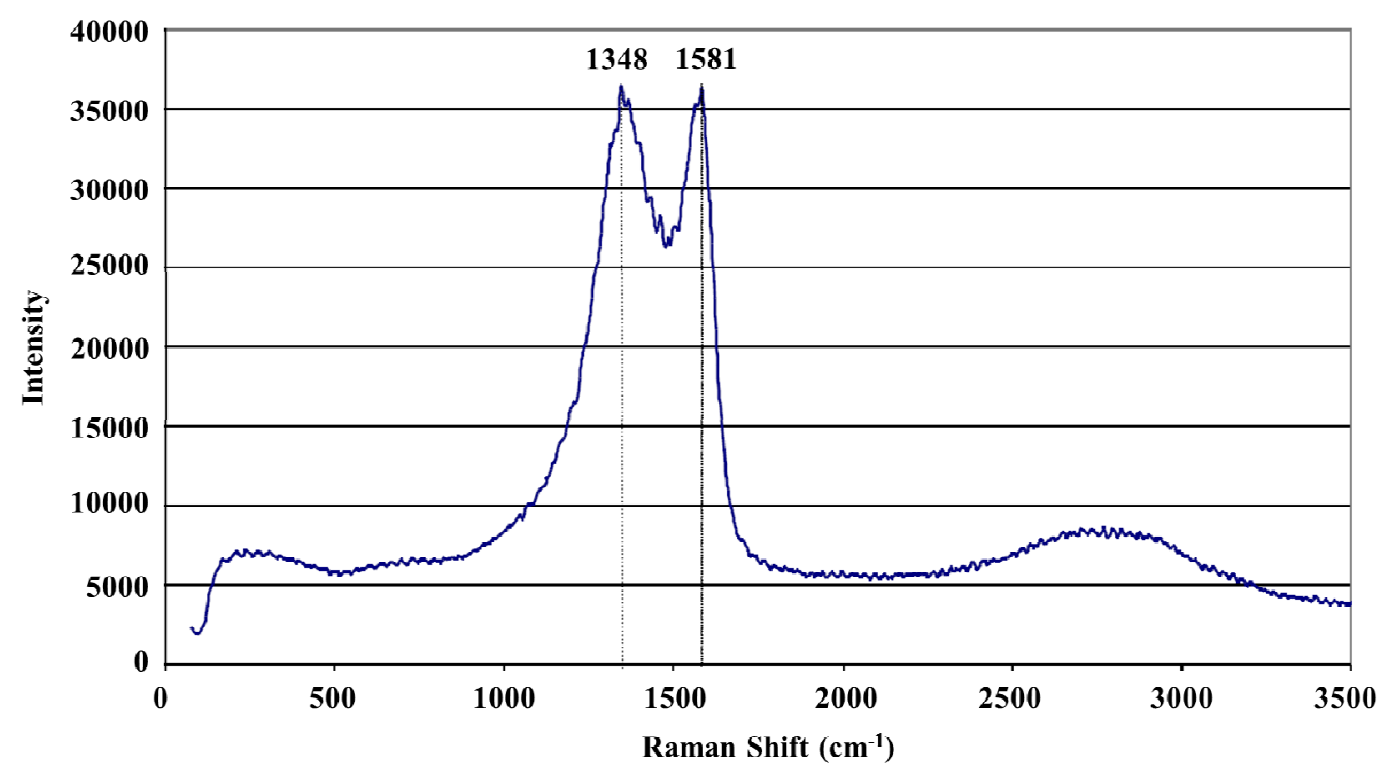

Figure 2b: Raman spectra of unsupported $\mathrm{BC}_{\mathrm{x}}$ films

Figure $2 \mathrm{~b}$ shows Raman spectrum of $\mathrm{BC}_{\mathrm{x}}$ films. The $\mathrm{BC}_{\mathrm{x}}$ sample displayed two peaks, the first, D-peak, at $1348 \mathrm{~cm}^{-1}$ and the second, G-peak, at $1581 \mathrm{~cm}^{-1}$. The G-peak represents inplane bond stretching vibrations of carbon atoms in graphite while the D-peak correlates to the vibrations of the defect carbon atoms, particularly the ones in a non-graphitic structure. The microcrystalline width $\left(\mathrm{L}_{\mathrm{a}}\right)$, which is a measure of the persistence of crystallinity parallel to the graphene-like plane, was calculated to be $4.4 \mathrm{~nm}$ based on the ratio of the two peaks intensities. 


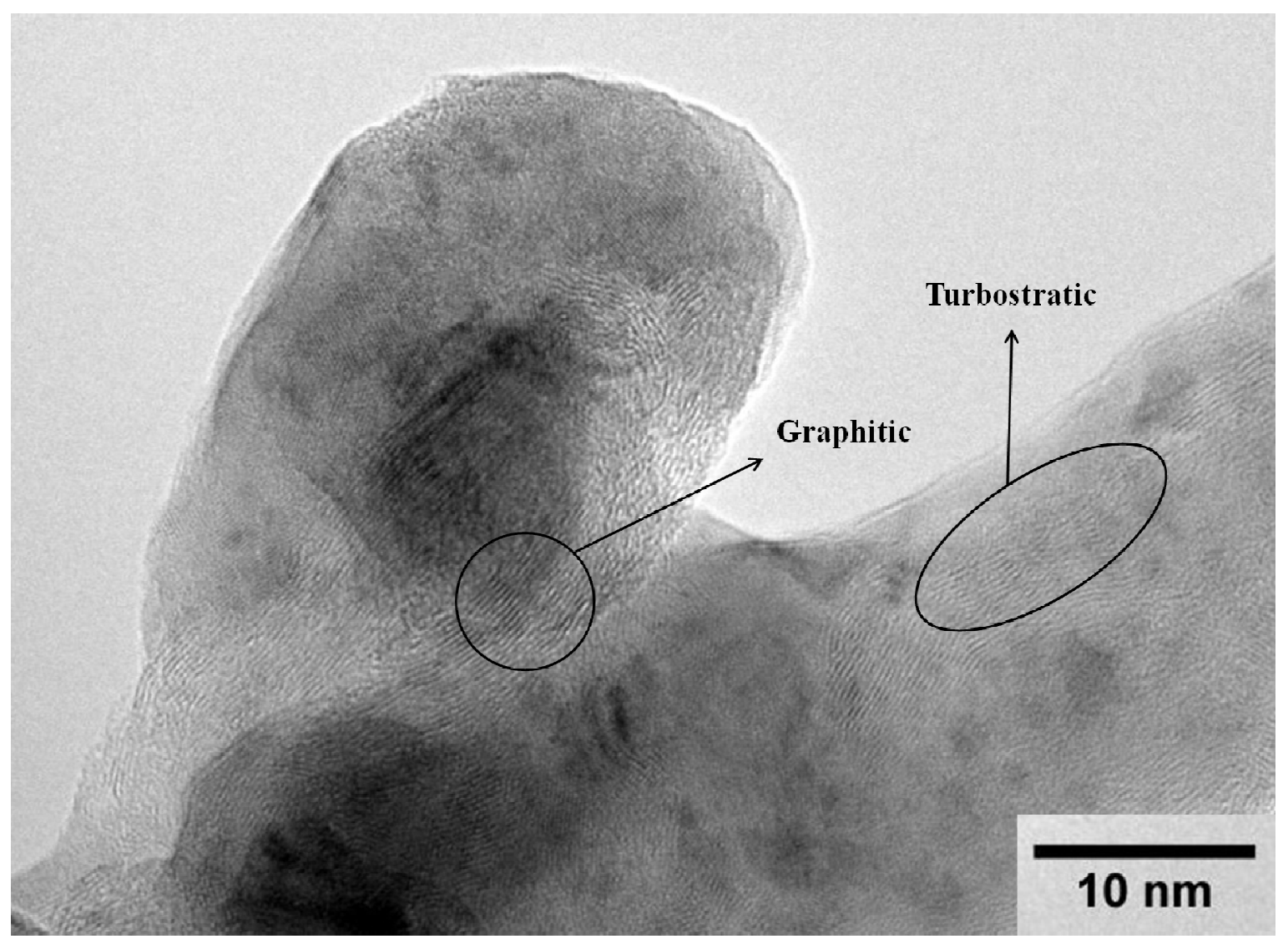

(a)

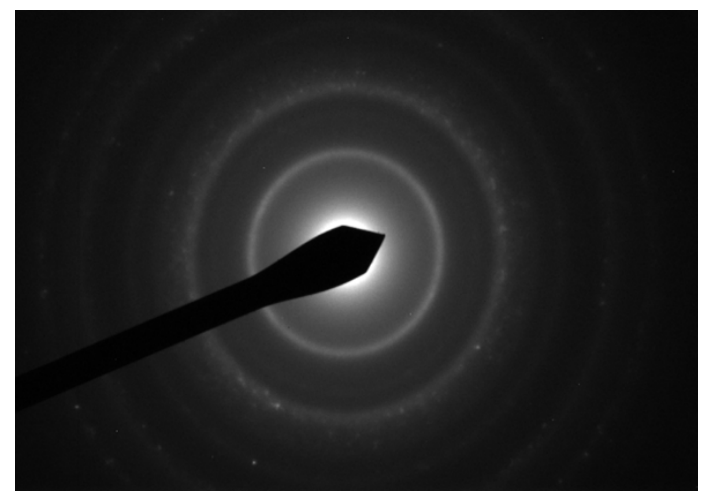

(b)

Figure 3: (a) TEM image of $\mathrm{BC}_{\mathrm{x}}$ film showing microcrystalline domains with turbostratic structure. (b) Electron diffraction of $\mathrm{BC}_{\mathrm{x}}$ film

Figure 3a shows high-resolution TEM micrographs of the $\mathrm{BC}_{\mathrm{x}}$ films. The image displays two distinct features of the $\mathrm{BC}_{\mathrm{x}}$ material: turbostratic and graphite-like components. The 
turbostratic nature of the carbon also can be seen in the image, note the preferential alignment of the graphene domains (Figure 3a). In addition, there were regions that were isotropic in nature and resembled disordered carbon. In general, the $\mathrm{TEM}$ images of $\mathrm{BC}_{\mathrm{x}}$ show domains that have short range order only, this local information correlates nicely with the bulk (average) information provided by the XRD diffraction patterns and Raman spectra.

During the growth of $\mathrm{BC}_{\mathrm{x}}$ flakes, the availability of boron depends on the decomposition rates of the reactant, $\mathrm{BCl}_{3}$, relative to the decomposition rate of benzene. In addition, $\mathrm{H}$ and $\mathrm{Cl}$ atoms in the gas phase are highly reactive and capable of etching carbon at either the edges of the planes of graphene. High concentrations of the free radicals of $\mathrm{H}, \mathrm{Cl}$ and $\mathrm{B}$ can promote apparent graphitization and ordering of the samples. The appearance of both graphitic and turbostratic domains suggests that in the reaction zone, the free radicals concentrations may not be uniformly distributed in the gas phase, thus allowing both domains to grow simultaneously.

The electron diffraction pattern gathered from the high resolution TEM is shown in Figure $3 b$. It has two significant rings, with the inner ring correlating to a d-layer spacing of $0.338 \mathrm{~nm}$. The rings are uniform, and discrete, and are commonly observed for polycrystalline materials. The resemblance between the measured d-spacing and that of the graphite is consistent with boron atoms having been substituted into the carbon structure. 


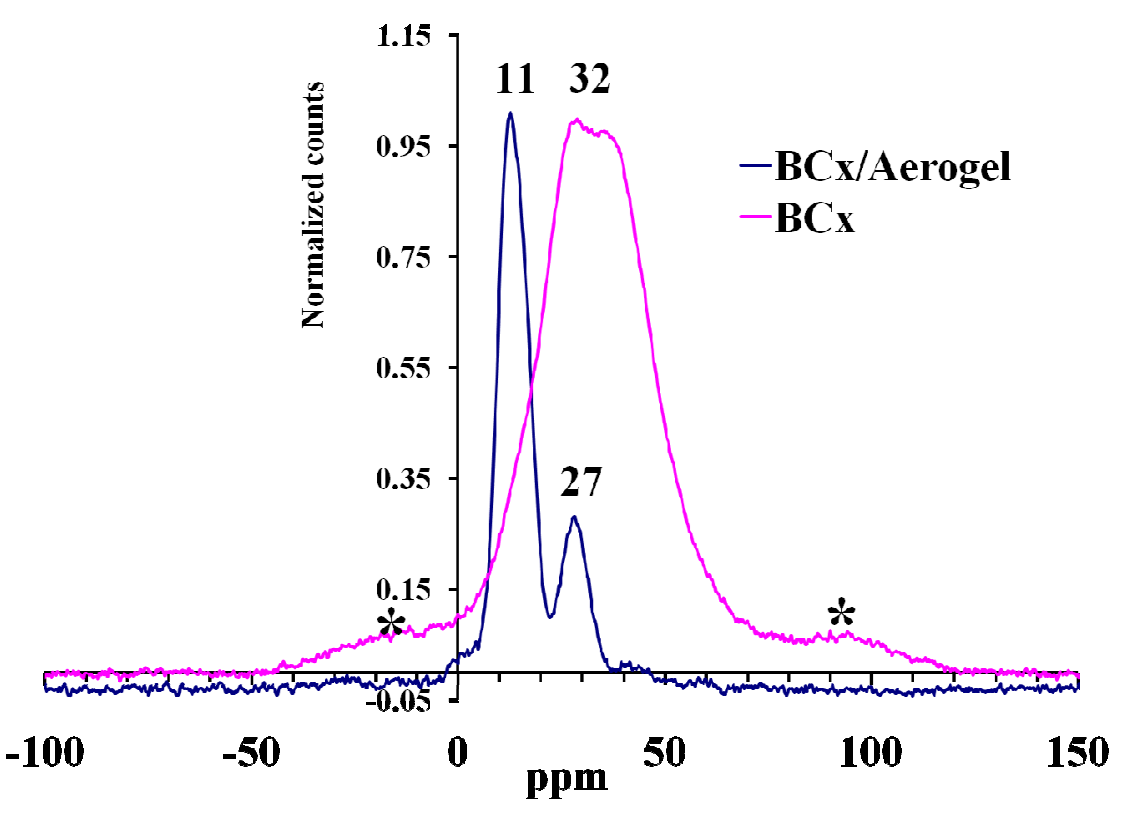

Figure 4a: Solid-State ${ }^{11} \mathrm{~B}$ NMR spectra of $\mathrm{BC}_{\mathrm{x}}$ films and $\mathrm{BC}_{\mathrm{x}} /$ Aerogel.

Solid-state ${ }^{11} \mathrm{~B}$ NMR studies were carried out to determine the chemical environment of boron atoms in $\mathrm{BC}_{\mathrm{x}}$. For nuclei like ${ }^{11} \mathrm{~B}$ that possess a nonzero quadrupole moment $\left(4.06 * 10^{-30}\right.$ $\mathrm{m}^{2}$ ), the predominant interaction is the quadrupole interaction, which is the interaction of the nucleus with the surrounding electric field gradient (EFG). Other interactions, such as dipoledipole coupling, can be averaged under magic angle spinning (MAS) conditions.

The non-zero quadrupole moment of ${ }^{11} \mathrm{~B}$ causes the nucleus to interact strongly with the surrounding EFG. While, to the first order, MAS can average the quadrupole interactions, the second-order quadrupole interactions significantly alter the central transition $(m=-1 / 2 \rightarrow 1 / 2)$. These cannot be averaged under MAS nor by spinning at any one fixed angle [42]. The resulting anisotropy then manifests itself in the NMR spectrum causing resonances to appear as broad MAS powder patterns and not as single isotropic peaks. For a nucleus in a symmetric chemical environment (octahedral or tetrahedral coordination with identical atoms) the interaction of EFG 
across the nucleus is uniform. Thus, the associated broadening is diminished. However, for a nucleus in an asymmetric environment like trigonal planar coordination, resonances can become significantly broadened [43].

The broadening effect has been observed for $\mathrm{BC}_{\mathrm{x}}$ materials before, however, due to the second order quadruple broadening of resonances in ${ }^{11} \mathrm{~B}$ NMR spectra, the individual contributions of B atoms were difficult to resolve. To obtain better resolution, we acquired these spectra at the highest available field strength (21.1 T), Figure 4a.

Analysis of the ${ }^{11} \mathrm{~B}$ MAS NMR spectra of a pure $\mathrm{BC}_{\mathrm{x}}$ indicated a single chemical environment as evidenced by a single resonance centered at $32 \mathrm{ppm}$ corresponding to boron bonded in a trigonal coordination $[44,45]$. The low-intensity peaks (marked with asterisks) on either side slightly overlap with the main resonance corresponds to spinning sidebands, which occur at integer multiples of the rotor spinning speed.

The structure of $\mathrm{BC}_{\mathrm{x}}$ after its deposition on a heterogeneous surface was further investigated by coating silica aerogel with $\mathrm{BC}_{\mathrm{x}}$ films. The concentration of boron is directly proportional to the area under NMR peak. The bulk concentration was calculated to be 15.9 at. $\%$ from NMR versus 17 at.\% from XPS. The two concentrations are close considering that the two techniques analyze different aspects of the sample. That there is a difference may be attributable to the difference in the sample area analyzed; NMR is a bulk or averaging analysis method while XPS is a surface or more localized method. Furthermore, it is reasonable to have higher concentrations at the surface stemming from boron species not substituted in the carbon network. Characterization by XPS verified two peaks that are attributed to doped boron, one denoted as substitutional boron and the other one as interstitial boron. It is the interstitial boron atoms at the edge sites that can result in a higher boron concentration on the surface than in the bulk. 
The effect of the coatings on the silica aerogel sample was investigated by comparing ${ }^{11} \mathrm{~B}$ NMR spectra before and after applying $\mathrm{BC}_{\mathrm{x}}$ coatings. In contrast to the bulk $\mathrm{BC}_{\mathrm{x}}$, the spectrum for the $\mathrm{BC}_{\mathrm{x}}$ coated aerogel is comprised of two nonequivalent sites as indicated by two wellresolved peaks centered at $\sim 11 \mathrm{ppm}$ and $\sim 27 \mathrm{ppm}$, respectively. The spectra of bulk $\mathrm{BC}_{\mathrm{x}}$ and $\mathrm{BC}_{\mathrm{x}}$-coated silica aerogel are overlaid in Figure $4 \mathrm{a}$. The difference between the bulk $\mathrm{BC}_{\mathrm{x}}$ and $\mathrm{BC}_{\mathrm{x}}$-coated aerogel is believed to result from a difference in structure between the two materials. Similar to graphite, $\mathrm{BC}_{\mathrm{x}}$ is organized in sheets and each layer is well ordered even though the 3D structure does not have long-range order in the direction perpendicular to the plane. The disordered nature of the material, therefore, causes resonances to become significantly broadened. In contrast to bulk $\mathrm{BC}_{\mathrm{x}}$, the $\mathrm{BC}_{\mathrm{x}}$ deposited on the aerogel exists in well-ordered sheets that have much narrower resonances. The difference in the chemical shift between the bulk $\mathrm{BC}_{\mathrm{x}}$ and the $\mathrm{BC}_{\mathrm{x}}$ coated silica aerogel may be the result of a difference in the average boron coordination between the two materials. This difference indicates that the $\mathrm{BC}_{\mathrm{x}}$-coated aerogel may undergo a partial conformational change from trigonal to tetrahedral coordination. The boron nucleus is sensitive to the electronic environment in which it resides. Therefore, when the local environment is altered, this change can be manifested in a varying chemical shift. For nuclei experiencing a nonzero quadrupole moment, or some other underlying anisotropy, there can also be a change in the symmetry of the peak, or in the peak width. A difference can be seen explicitly in the two spectra. When $\mathrm{Si}$ or $\mathrm{O}$ is present in the environment of the boron, a downfield shift of the peak is seen as well as a narrowing of both peaks. The lower field peak of bulk $\mathrm{BC}_{\mathrm{x}}$ located at $\sim 27 \mathrm{ppm}$ shifts down to $\sim 11 \mathrm{ppm}$ when the material is deposited on silica aerogel. The two distinct peaks for $\mathrm{BC}_{\mathrm{x}} /$ aerogel spectra represent trigonal boron sites with little, 
if any, tetrahedral sites present. As discussed earlier, tetrahedral boron displays resonances around $\sim 0 \mathrm{ppm}$. Here, the $\mathrm{BC}_{\mathrm{x}}$ coating appeared to consist only of trigonal boron.

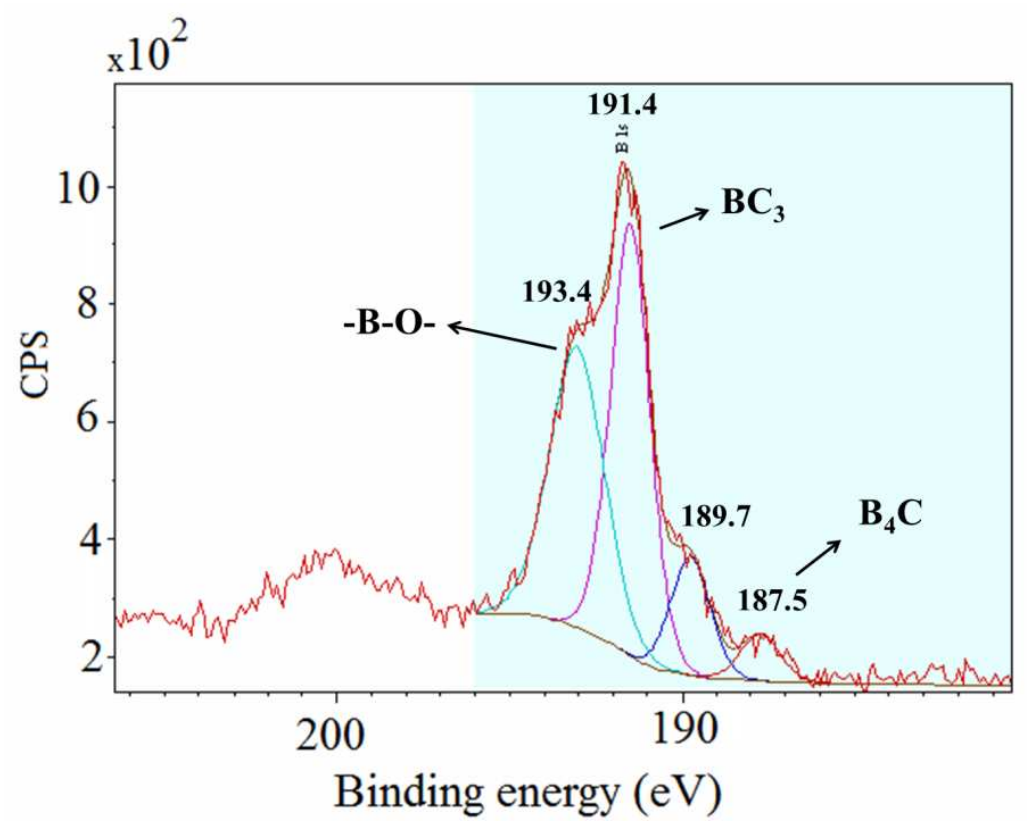

Figure 4b: XPS profile of $\mathrm{BC}_{\mathrm{x}}$ film. Deconvolution of the profile shows mainly $\mathrm{BC}_{3}$ along with boron oxide and a small hint of boron carbide

XPS was used to determine the chemical state of B in the framework, Figure 4b. Four deconvolution lines were used to obtain a good curve fit to the spectra. The different chemical states of boron corresponded to peaks centered at 187.5, 189.7, 191.4 and $193.4 \mathrm{eV}$, respectively. The 193.4 peak is attributed to -B-O- bonds with high strength whereas the lower energy peak $187.5 \mathrm{eV}$ is assigned to boron carbide bonds. The two middle peaks at 189.7 and 191.4 are typically attributed either to substitutional boron or interstitial (steps, edges or intercalated) boron. Based on comparative bond strength, the higher bond energy, $191.4 \mathrm{eV}$ has been attributed to the substitutional boron [28]. The carbon to boron ratio was determined to be 3 to 1 , which corresponds to what has been proposed in the literature for the CVD synthesis of $\mathrm{BC}_{\mathrm{x}}[9$, $10,28,46]$. 
The boron concentration in the $\mathrm{BC}_{\mathrm{x}}$ films was determined using XPS and solid-state ${ }^{11} \mathrm{~B}$ NMR. The concentration determined by solid-state NMR equates to the bulk concentration while XPS represents the first few atomic layers on the surface. The concentration determined by NMR was calculated using boric acid as the reference. The respective concentrations determined by solid-state NMR and XPS are reported alongside $\mathrm{d}_{002}$ lattice spacing obtained by XRD and TEM, Table 2. The concentrations are notably similar suggesting a fairly uniform structure.

Table 2: Boron concentration, substitution and lattice spacing calculated from XPS, ${ }^{11} \mathrm{~B}$ NMR, XRD and TEM ${ }^{*}$

\begin{tabular}{|l|l|l|l|l|l|}
\hline \multicolumn{3}{|l|}{ B Concentration } & \multicolumn{2}{l|}{ B:C Ratio } & \multicolumn{2}{l|}{$\mathrm{d}_{002}$ Lattice Spacing } \\
\hline XPS & ${ }^{11}$ B NMR & XPS & ${ }^{11}$ B NMR & XRD & TEM \\
\hline 17 & 15.9 & $1: 3$ & $1: 4.6$ & 0.344 & 0.338 \\
\hline
\end{tabular}

* XPS concentration correlates to atomic \%, NMR concentration correlates to weight $\%$, NMR ratios are not just the ratio of $\mathrm{B}: \mathrm{C}$, but with $\mathrm{B}$ to all other elements in the material, i.e. O. Thus, it is considered to be the lower concentration boundary

Table 3: Textural properties of carbon substrates AC and CS *

\begin{tabular}{|l|l|l|l|l|l|l|}
\hline Sample & $\begin{array}{l}\text { Mean } \\
\text { Pore Size } \\
(\mathrm{nm})\end{array}$ & $\begin{array}{l}\mathrm{N}_{2} \text { BET } \\
\text { SA }\left(\mathrm{m}^{2} / \mathrm{g}\right)\end{array}$ & PV $(\mathrm{cc} / \mathrm{g})$ & $\begin{array}{l}\text { Micro PV } \\
(\mathrm{cc} / \mathrm{g})\end{array}$ & $\begin{array}{l}\text { Meso PV } \\
(\mathrm{cc} / \mathrm{g})\end{array}$ & External SA $\left(\mathrm{m}^{2} / \mathrm{g}\right)$ \\
\hline $\mathrm{AC}$ & 0.67 & 1590 & 0.84 & 0.74 & 0.1 & 68 \\
\hline $\mathrm{CS}$ & 0.5 & 480 & 0.26 & 0.23 & 0.03 & 15 \\
\hline
\end{tabular}

* SA: Surface Area, PV: Pore Volume

* Mean pore size was determined by $\mathrm{CH}_{3} \mathrm{Cl}$ adsorption

Table 4: Change in weight, $\mathrm{N}_{2}$ BET surface area and $\mathrm{H}_{2}$ adsorption uptake of porous substrates before and after $\mathrm{BC}_{\mathrm{x}}$ deposition *

\begin{tabular}{|l|l|l|l|}
\hline Sample & $\mathrm{N}_{2}$ BET SA $\left(\mathrm{m}^{2} / \mathrm{g}\right)$ & $\begin{array}{l}\text { Weight gain by } \mathrm{BC}_{\mathrm{x}} \\
\text { deposition }(\%)\end{array}$ & $\begin{array}{l}\mathrm{H}_{2} \text { adsorption at 25 }{ }^{\circ} \mathrm{C} \\
\text { and } 100 \text { bar }(\mathrm{wt} \%)\end{array}$ \\
\hline $\mathrm{AC}$ & 1590 & - & 0.49 \\
\hline AC-B-10 & 841 & 7.0 & 0.36 \\
\hline AC-B-30 & 248 & 25.7 & 0.39 \\
\hline AC-B-60 & 113 & 48.0 & - \\
\hline CS & 480 & - & 0.25 \\
\hline CS-B-10 & 395 & 2.0 & 0.24 \\
\hline CS-B-30 & 231 & 5.3 & 0.26 \\
\hline CS-B-60 & 9 & 9.1 & - \\
\hline
\end{tabular}

* SA: Surface area 


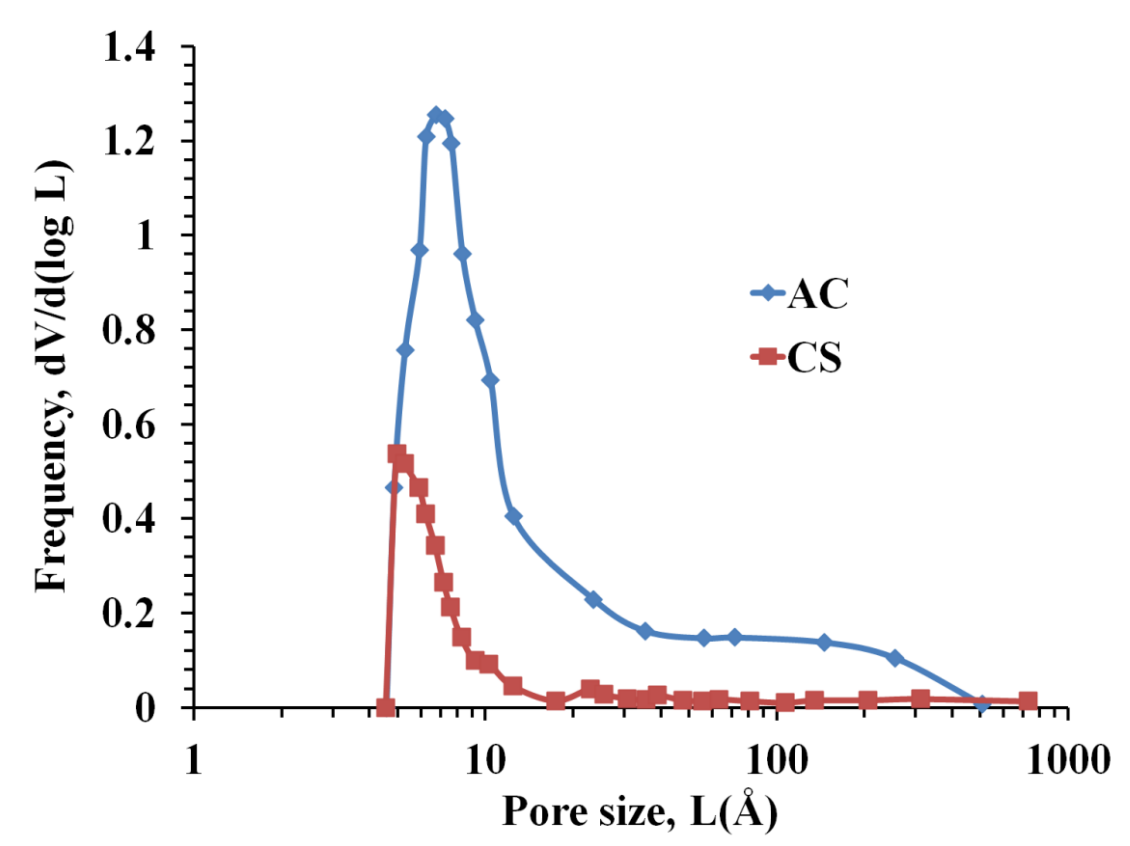

Figure 5: Pore size distribution of the carbon substrates $\mathrm{AC}$ and $\mathrm{CS}$ measured by $\mathrm{CH}_{3} \mathrm{Cl}$ adsorption [36].

\subsection{Hydrogen Adsorption on $\mathrm{BC}_{\mathrm{x}}$ Coated Carbon Substrates}

Textural properties of carbon substrates together with their pore size distributions are provided in Table 3 and Figure 5, respectively. AC possesses both micro and mesopore domains with a sharp micropore peak at $0.67 \mathrm{~nm}$ and a broad mesopore tail stretched over $40 \mathrm{~nm}$. Creation of the mesopores arises from the use of both PEG as the additive during synthesis and the $\mathrm{CO}_{2}$ oxidation/activation process that opens up inaccessible porosity and enlarges the existing micropores. Earlier studies have shown that the presence in the pore size distribution of such a mesopore "tail" induces a hierarchal pore structure with micropores connected to mesopore channels [47]. This significantly enhances accessibility of the pores and promotes the global rates molecular diffusion. On the other hand, since the majority of the porosity is still microporous within the ultra-micropore range, AC shows a high affinity for the adsorption of small molecules. Previous experimental measurements have suggested that a pore spacing of 
approximately $0.7 \mathrm{~nm}$ is the optimum pore size for hydrogen adsorption on carbons [48]. Hence, the average size of the micropores in AC falls near this so-called sweet spot.

The CS sample is purely microporous with mean pore size centered at $0.5 \mathrm{~nm}$. Since the CS sample was not activated, its surface area is lower than AC. The CS sample, synthesized via emulsion polymerization, formed spheres with an average diameter of $500 \mathrm{~nm}$. The morphology of the CS sample is shown in Figure 6.
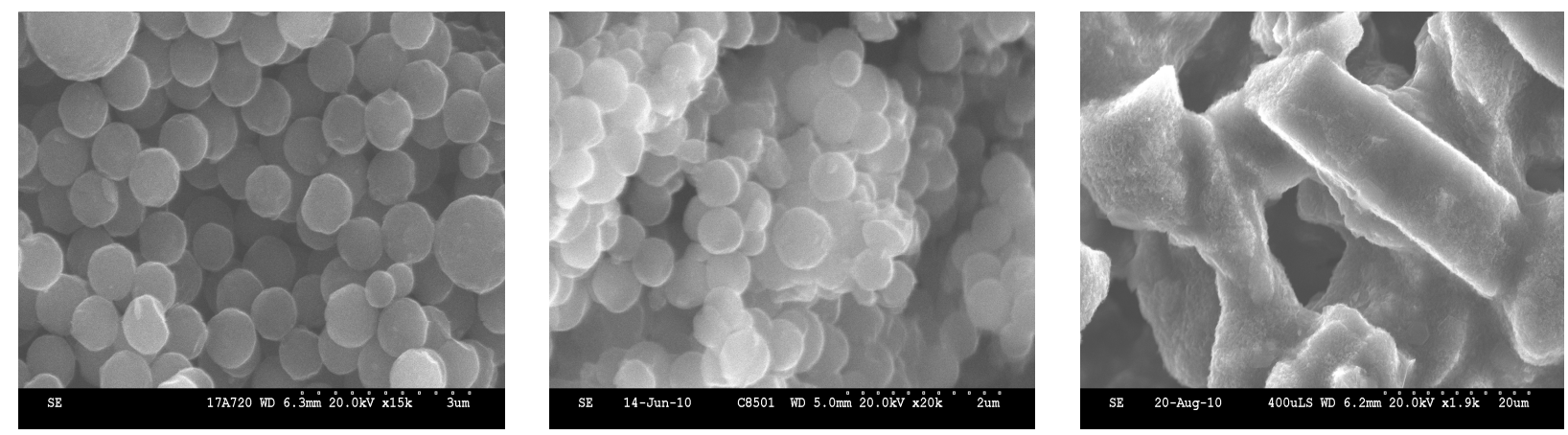

Figure 6: (a) CS, (b) CS-B-30, (c) CS-B-30 after 15 minutes burn off at $600{ }^{\circ} \mathrm{C}$ in air $(1000 \mathrm{ml} / \mathrm{min})$; note the differences in length scales between the images.

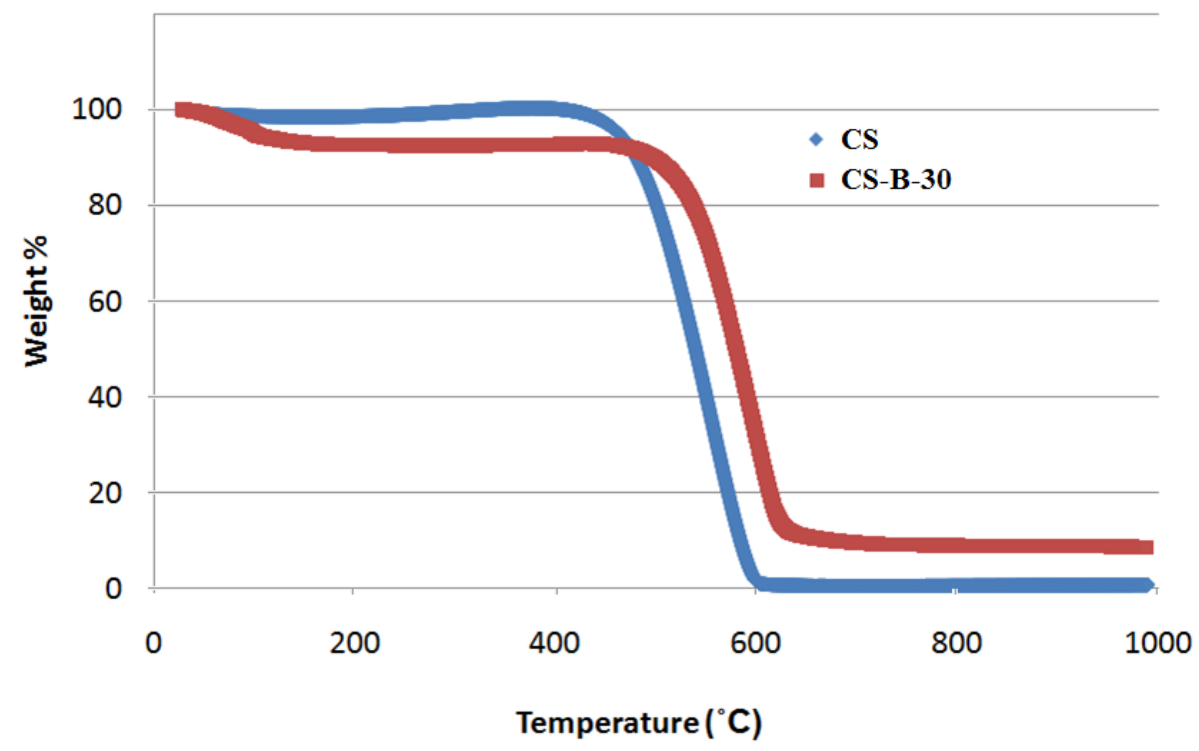

Figure 7: TGA-Air burn-off profiles for CS and CS-B-30 samples (flow rate $=100 \mathrm{cc} / \mathrm{min}$ ) 


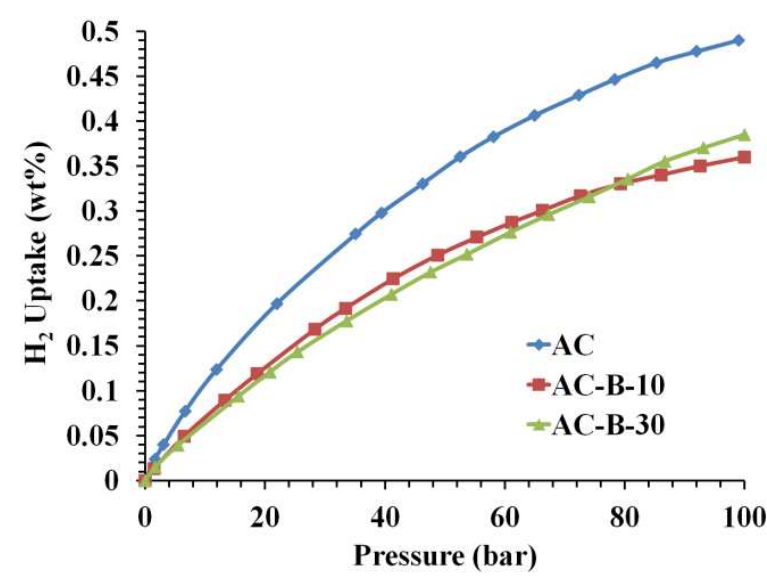

(a)

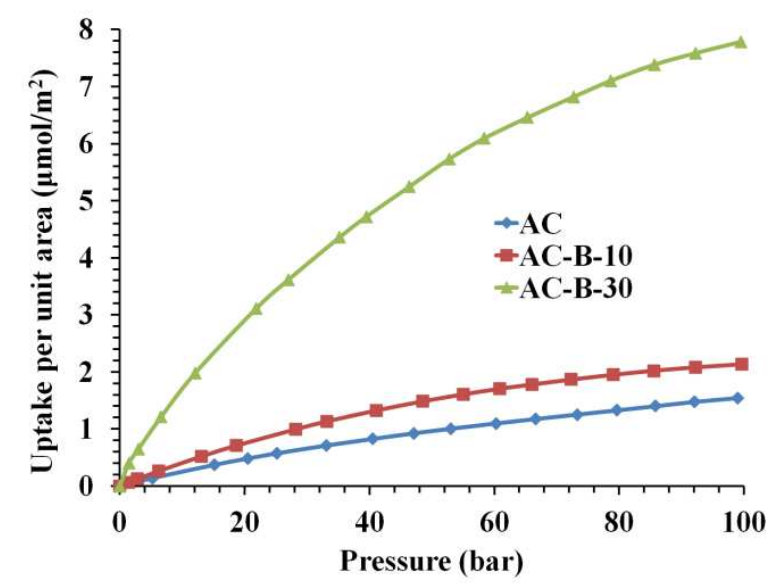

(c)

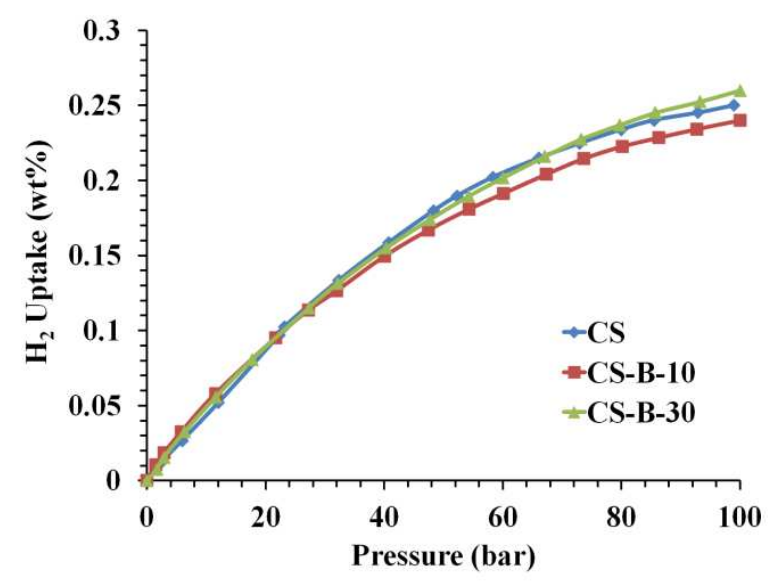

(b)

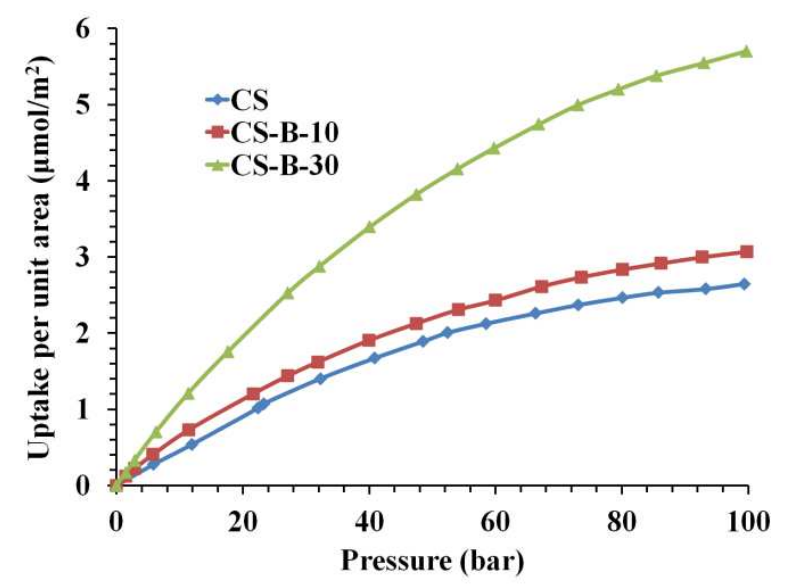

(d)

Figure 8: Hydrogen adsorption isotherms on $\mathrm{AC}$ and $\mathrm{CS}$ carbons and their derivatives at $25{ }^{\circ} \mathrm{C} . \mathrm{H}_{2}$ adsorption isotherms are reported in wt $\%(a, b)$ and $\mu \mathrm{mol} / \mathrm{m}^{2}(\mathrm{c}, \mathrm{d})$, respectively.

The deposits of $\mathrm{BC}_{\mathrm{x}}$ were produced on the carbons at different reaction times up to $1 \mathrm{hr}$. Weight gain of samples and their measured $\mathrm{N}_{2}$ BET surface area as a function of reaction times at 10, 30 and 60 minutes are provided in Table 4. Even for short reaction times, notable weight gains and significant reductions in surface area were measured. Additionally, reaction times as far as 60 minutes resulted in saturation of carbon surfaces with $\mathrm{BC}_{\mathrm{x}}$ deposition and clogging of most of the porosity for CS. Figure 6 compares morphology of the native CS sample and the CS 
sample after 30 minutes deposition of $\mathrm{BC}_{\mathrm{x}}$. Under this condition, the sample gained $5 \%$ in weight, while the morphology of the carbon remained almost intact.

Deposition of $\mathrm{BC}_{\mathrm{x}}$ on a carbon structure is reported to enhance the carbon's stability toward oxidation at high temperatures due to the anti-oxidative properties of $\mathrm{BC}_{\mathrm{x}}$ [25]. A burnoff test of the $\mathrm{BC}_{\mathrm{x}}$ coated CS sample (i.e. 15 minutes heat treatment under flowing air at $600{ }^{\circ} \mathrm{C}$ ) left a residue of $\mathrm{BC}_{\mathrm{x}}$, although during the process the CS sample lost its texture and morphology, Figure 6. This loss of texture can be attributed to the non-uniformity of deposition of $\mathrm{BC}_{\mathrm{x}}$ on the CS sample that allowed air to reach carbon cores resulting in their oxidation and burn-off.

TGA profiles were collected to quantify carbon burn-off as a function of temperature. Figure 7 shows TGA profiles of the CS sample before and after $\mathrm{BC}_{\mathrm{x}}$ deposition. The native CS started to burn in flowing air at nearly $400{ }^{\circ} \mathrm{C}$ whereas the $\mathrm{BC}_{\mathrm{x}}$ coatings delayed the initial oxidation and burn-off for the CS-B-30 sample with a shift of at least $50{ }^{\circ} \mathrm{C}$. Additionally, although pure CS leaves no residue at $600{ }^{\circ} \mathrm{C}$, the CS-B-30 sample retains nearly $10 \%$ of its original weight.

Hydrogen adsorption isotherms on the synthesized carbon substrates and the coated carbons were performed at room temperature. The hydrogen uptakes on the carbon samples at 25 ${ }^{\circ} \mathrm{C}$ and 100 bar are summarized in Table 4.

Figures $8 \mathrm{a}$ and $8 \mathrm{~b}$ show $\mathrm{H}_{2}$ adsorption uptakes on the native carbons as well as the ones coated with $\mathrm{BC}_{\mathrm{x}}$ for 10 and 30 minutes. For the activated carbon, $\mathrm{AC}$, the $\mathrm{H}_{2}$ adsorption uptake on the native carbon stands higher than that of the $\mathrm{BC}_{\mathrm{x}}$ coated samples. Considering that the coated samples have lost a significant amount of their original accessible surface area, as provided in Table 4, it is notable that they still store $\mathrm{H}_{2}$ at capacities of as high as 0.35-0.4 wt\%. The results for the CS samples are similar. Although upon coating with $\mathrm{BC}_{\mathrm{x}}$ for 30 minutes the 
CS carbon lost up to $50 \%$ of its original accessible surface area, still the total $\mathrm{H}_{2}$ adsorption uptake remained close to the original uptake. To investigate the effects of boron substitution on $\mathrm{H}_{2}$ adsorption affinity of the adsorbents, we normalized the adsorption uptakes with respect to the accessible surface area of the samples. Figures $8 \mathrm{c}$ and $8 \mathrm{~d}$ show hydrogen adsorption isotherms normalized by the $\mathrm{N}_{2}$ BET surface area of the adsorbents. Gas uptakes are reported in the number of moles of hydrogen adsorbed per unit surface area of the adsorbent. In all cases, the coating of carbon substrates resulted in the reduction of surface area, which, accordingly, reduced total adsorption capacity of the adsorbent. However, the adsorption capacity of hydrogen per unit surface area of the adsorbent was significantly increased as a result of surface modification with $\mathrm{BC}_{\mathrm{x}}$ coatings. Previous studies of the incorporation of heteroatoms, including $\mathrm{Li}, \mathrm{Na}$ and $\mathrm{K}$, in PFA-derived carbons have indicated that the hydrogen adsorption capacity per unit surface area of the carbons can increase by as much as $20 \%$ [49]. However, with $\mathrm{BC}_{\mathrm{x}}$ we find an increase in hydrogen adsorption capacity per unit area that on CS-B-60 is over five times higher than on the native carbon, CS. This increase is quite significant scientifically. For practical applications, if we could prepare these $\mathrm{BC}_{\mathrm{x}}$ materials with higher surface area much higher levels of room temperature hydrogen adsorption could be attained. We get a hint of this potential with the AC-B-10 sample, as it shows the most promising hydrogen adsorption uptake due to its retained surface area (e.g. $800 \mathrm{~m}^{2} / \mathrm{g}$ ). 


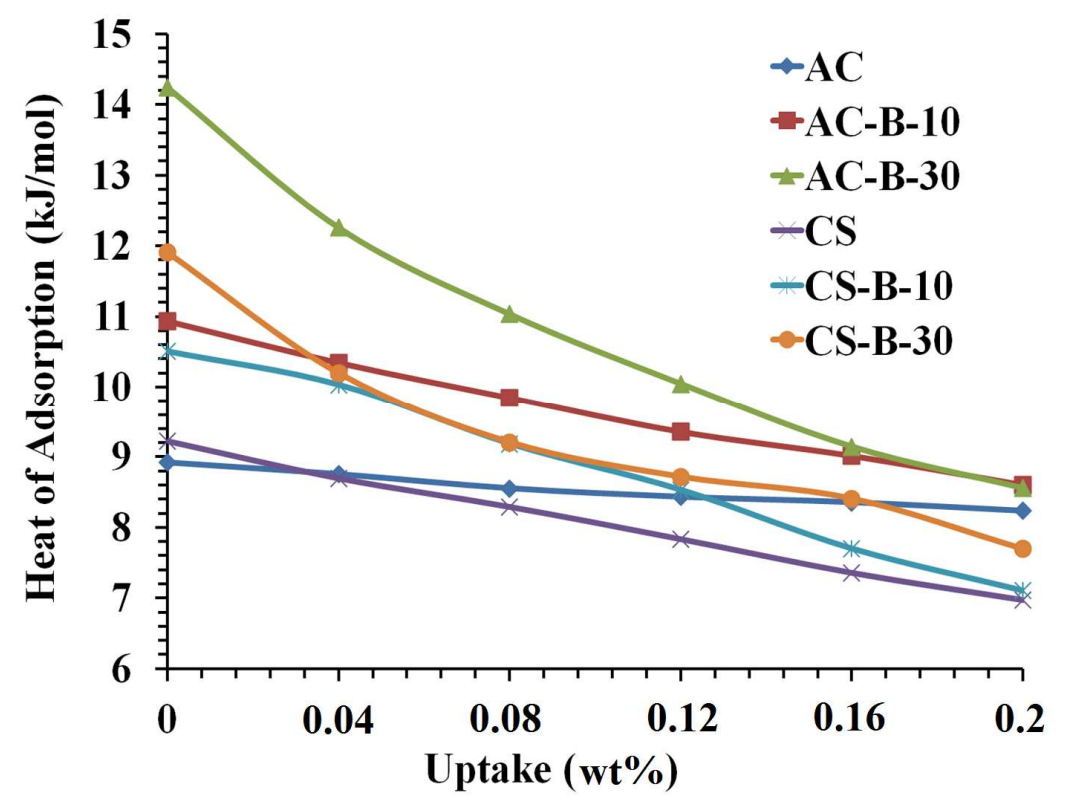

Figure 9: Heat of adsorption profiles calculated using $\mathrm{H}_{2}$ adsorption isotherms at 0 and $25^{\circ} \mathrm{C}$

Figure 9 shows the hydrogen heat of adsorption profiles for the carbons at room temperature. The heat of adsorption profiles are scaled based on the total hydrogen adsorption uptake. As suggested earlier, hydrogen heat of adsorption above $15 \mathrm{~kJ} / \mathrm{mol}$ is appropriate for reversible hydrogen storage operating between atmospheric pressure and 100 bar. Although native carbons at best possess heats of adsorption of 6-9 $\mathrm{kJ} / \mathrm{mol}$, after $\mathrm{BC}_{\mathrm{x}}$ deposition the heat of adsorption was increased to more than $12 \mathrm{~kJ} / \mathrm{mol}$. Among these samples, the AC-B-30 was the closest to a desirable adsorbent for hydrogen storage with an initial heat of adsorption of over 14 $\mathrm{kJ} / \mathrm{mol}$ and a surface area of $248 \mathrm{~m}^{2} / \mathrm{g}$. 


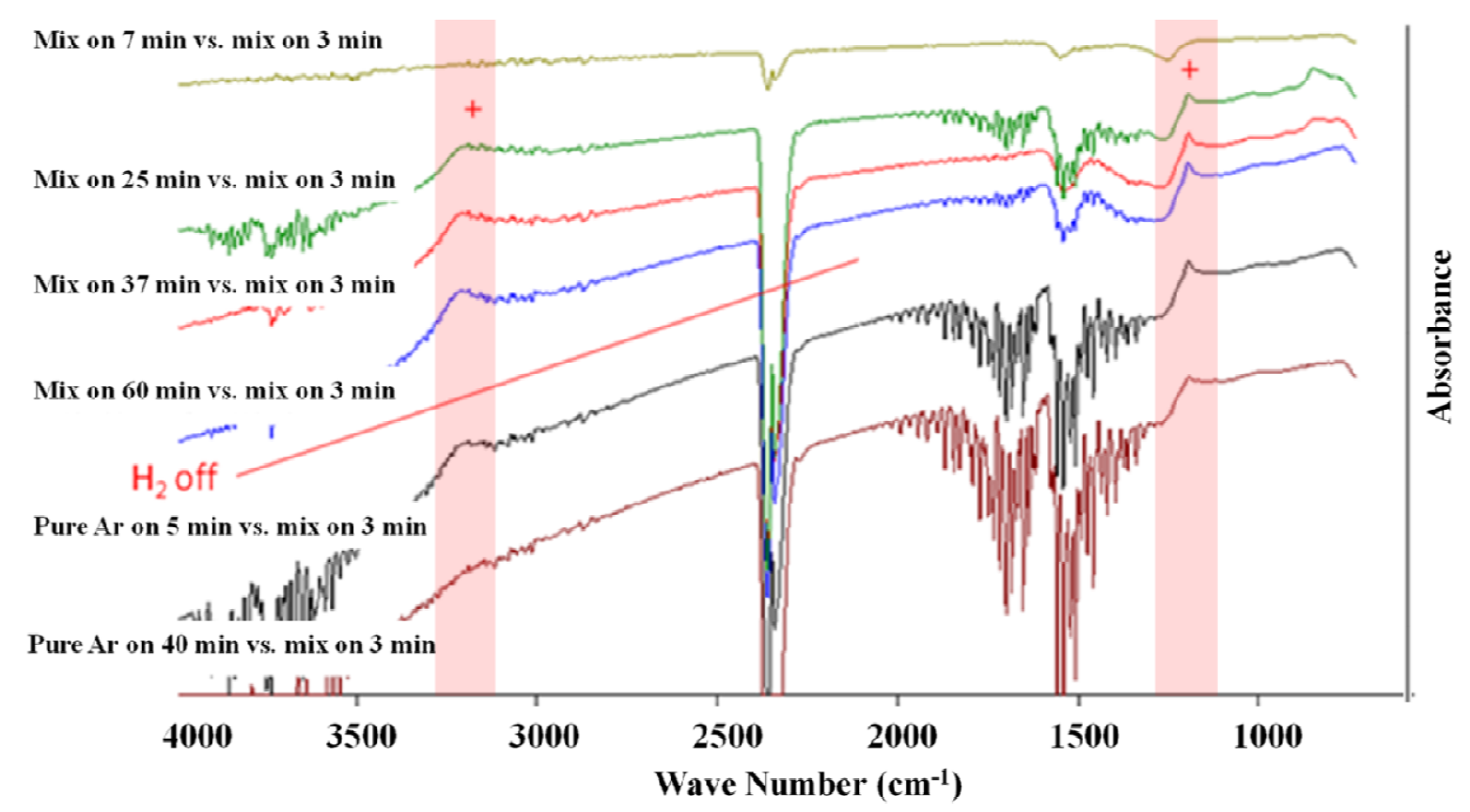

Figure 10: (Mix: $\mathrm{H}_{2} /$ Ar mixture with 5 vol $\% \mathrm{H}_{2}$ ) DRIFTs spectra for $\mathrm{H}_{2}$ adsorption on $\mathrm{BC}_{\mathrm{x}}$. Sample: $\mathrm{BC}_{\mathrm{x}}$ coated AC (30 min reaction), AC-B-30; Sample is cleaned under Pure Ar at $200{ }^{\circ} \mathrm{C}$; (1) 3 minutes after sample was cooled down to $30{ }^{\circ} \mathrm{C}$, transmission spectra was recorded; (2) The sample was exposed to $\mathrm{H}_{2} / \mathrm{Ar}$ mixture. Two peaks at 3200 and $1190 \mathrm{~cm}^{-1}$ appeared. (3) By purging the sample and removing hydrogen gas from the chamber, both peaks begin to disappear.

A DRIFTs analysis provided more details about the nature of the interactions between hydrogen molecules and $\mathrm{BC}_{\mathrm{x}}$ structure. For this analysis, the $\mathrm{AC}-\mathrm{B}-30$ sample was used. Figure 10 shows DRIFTs profiles collected at different times during exposure of the sample to hydrogen gas. After cleaning the sample and cooling it down to $30{ }^{\circ} \mathrm{C}$ under argon, the sample was dosed with the $\mathrm{H}_{2}$ /Ar mixture. Upon introducing $\mathrm{H}_{2} /$ Ar to the sample, two peaks at wavenumbers 3200 and $1190 \mathrm{~cm}^{-1}$ appeared. The band at 3200 is attributed to an $\mathrm{H}-\mathrm{C}$ interaction and the lower frequency interaction at 1190 is attributed to wagging hydrogen molecule near a boron atom in a C-B-C bond structure. The sample was exposed to $\mathrm{H}_{2} / \mathrm{Ar}$ stream for 60 minutes. Then the gas was switched back to Ar to sweep $\mathrm{H}_{2}$ from the surface. As the IR absorbance spectra show 
(Figure 10), after 40 minutes of sweeping with inert gas both peaks disappeared indicating that adsorption of hydrogen on the $\mathrm{BC}_{\mathrm{x}}$ surface was reversible.

\section{Summary and Conclusions}

Boron doped carbon deposits were synthesized and characterized to study their effect on $\mathrm{H}_{2}$ adsorption properties of the carbons. On carbon substrates, the $\mathrm{BC}_{\mathrm{x}}$ coatings changed the nature of the carbon by protecting the underlying carbon from oxidation. The ${ }^{11} \mathrm{~B}$ NMR studies on the silica aerogel sample showed that two peaks appeared at 11 and $27 \mathrm{ppm}$ on the NMR spectra, compared to the single peak for bulk $\mathrm{BC}_{\mathrm{x}}$ at $32 \mathrm{ppm}$. The shifts were attributed to the asymmetric environment of boron atoms. In addition, the shifts on the $\mathrm{BC}_{\mathrm{x}}$ deposits were intervened by the presence of oxygen and silica atoms resulting in lower shifts compared to bulk $\mathrm{BC}_{\mathrm{x}} \cdot \mathrm{BC}_{\mathrm{x}}$ deposition on porous carbon substrates reduced surface area and increased the hydrogen heat of adsorption of the carbons. Among two carbons, AC, the activated carbon with mesopore domains admitted more $\mathrm{BC}_{\mathrm{x}}$ deposits and showed better hydrogen adsorption performance. Deposition of $\mathrm{AC}$ with $\mathrm{BC}_{\mathrm{x}}$ for 30 minutes increased the initial heat of adsorption of the carbon from $9 \mathrm{~kJ} / \mathrm{mol}$ to over $14 \mathrm{~kJ} / \mathrm{mol}$ while the adsorbent still possessed surface area of $248 \mathrm{~m}^{2} / \mathrm{g}$. DRIFTs analysis of $\mathrm{BC}_{\mathrm{x}}$ coated $\mathrm{AC}$ revealed that upon $\mathrm{H}_{2}$ adsorption two peaks at the wavenumbers 3200 and $1190 \mathrm{~cm}^{-1}$ did arise suggesting interactions of $\mathrm{H}_{2}$ with carbon and boron atoms, respectively. By sweeping $\mathrm{H}_{2}$ with argon, both peaks disappeared to confirm reversible nature of $\mathrm{H}_{2}$ adsorption on $\mathrm{BC}_{\mathrm{x}}$ coatings. 
These results are promising because they indicate that with better methods of contacting porous substrates with reactive gases, more complete coverage of their interior surfaces with $\mathrm{BC}_{\mathrm{x}}$ may be attained. Finely tuned activated carbons, carbide-derived carbons, MOFs doped with unsaturated metal sites and platinum embedded MOFs and activated carbons are examples of state-of-the-art adsorbents of $\mathrm{H}_{2}$ for mobile applications [50-52]. $\mathrm{Mn}(\mathrm{btt})\left(\mathrm{BTT}^{3-}=1,3,5\right.$ benzenetristetrazolate) with the BET surface area of $2100 \mathrm{~m}^{2} / \mathrm{g}$ and initial heat of adsorption of $10.1 \mathrm{~kJ} / \mathrm{mol}$ has been reported to achieve excess $\mathrm{H}_{2}$ adsorption capacity of $0.8 \mathrm{wt} \%$ at room temperature and 90 bar. Carbide-derived carbons with surface areas $\sim 2000 \mathrm{~m}^{2} / \mathrm{g}$, a narrow pore size close to $0.5 \mathrm{~nm}$ and an initial heat of adsorption of $\sim 12 \mathrm{~kJ} / \mathrm{mol}$ also have been reported to store $0.75 \mathrm{wt} \% \mathrm{H}_{2}$ at room temperature and 60 bar [48]. Platinum embedded IRMOF and activated carbons with surface areas above $2000 \mathrm{~m}^{2} / \mathrm{g}$ have exhibited $\mathrm{H}_{2}$ adsorption capacities of $0.7 \mathrm{wt} \%$ at100 bar.

In a comparison, the carbons synthesized and characterized in this work, AC and CS, have $\mathrm{H}_{2}$ adsorption capacities of 0.49 and $0.25 \mathrm{wt} \%$, respectively, at room temperature and 100 bar. Although after coating the carbons with $\mathrm{BC}_{\mathrm{x}}$ for 30 minutes their surface areas dropped to 248 and $231 \mathrm{~m}^{2} / \mathrm{g}$, respectively, they preserved much of their $\mathrm{H}_{2}$ adsorption capacities of 0.39 and $0.26 \mathrm{wt} \%$. Taking into account the loss of surface area, we can see that for a carbon with both a similar $\mathrm{BC}_{\mathrm{x}}$ coating and a BET surface area of $2000 \mathrm{~m}^{2} / \mathrm{g}$, the total uptake of hydrogen could be above $3 \mathrm{wt} \%$, at room temperature and $100 \mathrm{bar}$.

Thus with better and more complete $\mathrm{BC}_{\mathrm{x}}$ coverage will come even higher hydrogen loadings per unit area and per unit mass, thus making the storage of hydrogen as a fuel for mobile applications more viable. 


\section{Acknowledgements}

A portion of this research was performed at EMSL, a DOE Office of Science user facility sponsored by the Office of Biological and Environmental Research and located at Pacific Northwest National Laboratory.

\section{References}

[1] Wang L, Yang RT. Hydrogen Storage on Carbon-Based Adsorbents and Storage at Ambient Temperature by Hydrogen Spillover. Catalysis Reviews: Science and Engineering, 52(4): 411461

[2] Bhatia SK, Myers AL. Optimum Conditions for Adsorptive Storage. Langmuir, 2006; 22(4) 1688-1700

[3] Benard P, Chahine R. Determination of the adsorption isotherms of hydrogen on activated carbons above the critical temperature of the adsorbate over wide temperature and pressure ranges. Langmuir 2001; 17: 1950

[4] Kuchta B, Firlej L, Roszak Sz, Pfeifer P. A review of boron enhanced nanoporous carbons for hydrogen adsorption: numerical perspective. Adsorption 2010; 16:413-421

[5] Firlej L, Roszak Sz, Kuchta B, Pfeifer P, Wexler C. Enhanced hydrogen adsorption in boron substituted carbon nanospaces. The Journal of Chemical Physics 2009; 133: 164702

[6] Lee $\mathrm{H}$. Enhancement of $\mathrm{H}_{2}$ adsorption on a boron-doped carbon system for hydrogen storage. Solid State Communications 2010; 150:1959-1962

[7] Wu H, Fan X, Kuo J, Deng W. DFT Study of Hydrogen Storage by Spillover on Graphene with Boron Substitution. J. Phys. Chem. C 2011; 115: 9241-9249

[8] Bult JB, Lee J, O'Neill K, Engtrakul C, Hurst KE, Zhao Y, et al. Manipulation of Hydrogen Binding Energy and Desorption Kinetics by Boron Doping of High Surface Area Carbon. J. Phys. Chem. C 2012; 116: 26138-26143

[9] Chung TC Mike, Jeong Y, Chen Q, Kleinhammes A, Wu Y. Synthesis of Microporous Boron-Substituted Carbon (B/C) Materials Using Polymeric Precursors for Hydrogen Physisorption. J. Am. Chem. Soc. 2008; 130: 6668-6669

[10] Jeong Y, Chung TC Mike. The synthesis and characterization of super-activated carbon containing substitutional boron $\left(\mathrm{BC}_{\mathrm{x}}\right)$ and its applications in hydrogen storage. Carbon 2010; 48 : 2526-2537 
[11] Kleinhammes A, Anderson RJ, Chen Q, Jeong Y, Chung TC Mike, Wu Y. Enhanced Binding Energy and Slow Kinetics of $\mathrm{H}_{2}$ in Boron-Substituted Graphitic Carbon. J. Phys. Chem. C 2010; 114: 13705-13708

[12] Sankaran M, Viswanathan B. Hydrogen storage in boron substituted carbon nanotubes. Carbon 2007; 45: 1628-1635

[13] Kouvetakis J, Kaner RB, Sattler ML, Bartlett N. A novel Graphite-like Material of Composition $\mathrm{BC}_{3}$ and Nitrogen-Carbon Graphites. J. Chem. Soc., Chem. Commun. 1986; 17581759

[14] Kaner RB, Kouvetakis J, Warble CE, Sattler ML, Bartlett N. Boron-Carbon-Nitrogen Materials of Graphite-Like Structure. Materials Research Bulletin 1987; 22:399-404

[15] Mikhaylushkin AS, Zhang XW, Zunger A. Crystal structures and metastability of carbonboron compounds $\mathrm{C}_{3} \mathrm{~B}$ and $\mathrm{C}_{5} \mathrm{~B}$. Phys. Rev. B 2013; 87(9): 094103

[16] Hu QK, Wu QH, Ma YM, Zhang LJ, Liu ZY, He JL, et al. First-principles studies of structural and electronic properties of hexagonal $\mathrm{BC}_{5}$. Phys. Rev. B 2006; 73(21): 214116

[17] Zinin PV, Liu XR, Ming LC, Sharma SK, Liu Y, Hong SM. Ultraviolet and visible Raman spectroscopic of the graphitic $\mathrm{BC}_{\mathrm{x}}$ phases. Diamond and Related Materials 2009; 18: 1123-1128

[18] Naeini JG, Way BM, Dahn JR, Irwin JC. Raman scattering from boron-substituted carbon films. Phys. Rev. B 1996; 54(1): 144-151

[19] Wang H, Guo Q, Yang J, Zhao Y, Wang X, Tao Z, et al. Microstructure and thermophysical properties of $\mathrm{B}_{4} \mathrm{C} /$ graphite composites containing substitutional boron. Carbon 2013; 52: 10-16

[20] Fergus JW, Worrell WL. Silicon-carbide / boron-containing coatings for the oxidation protection of graphite. Carbon 1994; 33(4): 537-543

[21] Lowell CE. Solid Solution of Boron in Graphite. Journal of America Ceramic Society 1966; 50(3): 142-144

[22] Fecko DL, Jones LE, Thrower PA. The formation and oxidation of $\mathrm{BC}_{3}$, A new graphite like material. Carbon 1993; 31(4): 637-644

[23] Jones LE, Thrower PA. Influence of boron on carbon fiber microstructure, physical properties, and oxidation behavior. Carbon 1991; 29(2): 251-269

[24] Hach CT, Jones LE, Crossland C, Thrower PA. An investigation of vapor deposited boron rich carbon - novel graphite-like material - part $\mathrm{I}$ : the structure of $\mathrm{BC}_{\mathrm{x}}\left(\mathrm{C}_{6} \mathrm{~B}\right)$ thin films. Carbon 1999; 37: 221-230

[25] Radovic LR, Karra M, Skokova K, Thrower PA. The role of substitutional Boron in Carbon Oxidation. Carbon 1998; 36(12): 1841-1854

[26] Wang Q, Ma XL, Chen LQ, Cermignani W, Pantano CG. Effect of boron on graphite oxidation - a theoretical study. Carbon 1997; 35(2): 307-313

[27] Ma X, Wang Q, Chen LQ, Cermignani W, Schobert HH, Pantano CG. Semi-empirical studies on electronic structures of a boron-doped graphite layer - Implications on the oxidation mechanism. Carbon 1997; 35(10-11): 1517-1525

[28] Cermignani W, Paulson TE, Onneby C, Pantano CG. Synthesis and characterization of boron-doped carbons. Carbon 1995; 33(4): 367-374 
[29] Shirasaki T, Derre A, Menetrier M, Tressaud A, Flandrois S. Synthesis and characterization of boron-substituted carbons. Carbon 2000; 38: 1461-1467

[30] Liu Y, Zhang L, Cheng L, Yang W, Xu Y. Effect of deposition temperature on boron-doped carbon coatings deposited from a $\mathrm{BCl}_{3}-\mathrm{C}_{3} \mathrm{H}_{6}-\mathrm{H}_{2}$ mixture using low pressure chemical vapor deposition. Applied Surface Science 2009; 255: 8761-8768

[31] Xiao J, Su K, Liu Y, Ren H, Zeng Q, Cheng L, et al. Decomposition reaction rate of $\mathrm{BCl}_{3^{-}}$ $\mathrm{C}_{3} \mathrm{H}_{6}$ (propene) $-\mathrm{H}_{2}$ in the gas phase. J. of Phys. Chem. A. 2012; 116: 6955-6966

[32] Lorenzo-Castello D, Kamalakaran R, van Benthem K, Jin Phillipp Y, Grobert N, Ruhle M. Preparation and characterization of novel "sea-cucumber"-like structures containing carbon and boron. Carbon 2004; 42: 2223-2231

[33] Burgass JS, Acharya CK, Lizarazo J, Yancey N, Flowers B, Kwon G, et al. Boron doped carbon powders formed at $1000{ }^{\circ} \mathrm{C}$ and one atmosphere. Carbon 2008; 46: 1711-1717

[34] Bastl Z, Andera V. Production of boron carbides by IR laser-induced gas phase reactions. Diamonds and Related Materials 1995; 4: 917-920

[35] $\mathrm{Xu} \mathrm{L,} \mathrm{Wu} \mathrm{J,} \mathrm{Bai} \mathrm{S.} \mathrm{Fabrication} \mathrm{and} \mathrm{microstructure} \mathrm{of} \mathrm{boron-doped} \mathrm{isotropic} \mathrm{pyrolytic}$ carbon. Carbon 2012; 50: 4705-4710

[36] Strano MS, Agrawal H, Pedrick J, Redman D, Foley HC. Templated pyrolytic carbon: the effect of poly(ethylene glycol) molecular weight on the pore size distribution of poly(furfuryl alcohol)-derived carbon. Carbon 2003; 41(13): 2501-2508

[37] Qajar A, Peer M, Rajagopalan R, Foley HC. Characterization of Micro and Mesoporous Materials Using Accelerated Dynamics Adsorption, Langmuir 2013; 29(40): 12400-12409

[38] Hua C, Sedghi S, Madanib SH, Silvestre-Albero A, Sakamoto H, Kwong Ph, et al. Control of the pore size distribution and its spatial homogeneity in particulate activated carbon. Carbon 2014; 78: 113-120

[39] Peer M, Qajar A, Rajagopalan R, Foley HC. On the effects of emulsion polymerization of furfuryl alcohol on the formation of carbon spheres and other structures derived by pyrolysis of polyfurfuryl alcohol. Carbon 2013; 51: 85-93

[40] Qajar A, Peer M, Rajagopalan R, Foley HC. High pressure hydrogen adsorption apparatus: Design and error analysis. International Journal of Hydrogen Energy 2012; 37(11): 9123-9136

[41] Oya A, Marsh H. Review: phenomena of catalytic graphitization. Journal of Materials Science 1982. 17:309-322.

[42] Kennedy JD. Multinuclear NMR. 2nd ed. Multinuclear NMR, ed. J. Mason. 1989, New York: Plenum Publishing Company. 631

[43] Fyfe CA. Solid State NMR For Chemists. 1983, Guelph, Ontario: C.F.C. Press. 593

[44] Hermanek S. Boron-11 NMR spectra of boranes, main-group heteroboranes, and substituted derivatives. Factors influencing chemical shifts of skeletal atoms. Chem. Rev., 1992; 92(2): 325362

[45] Bryce DL, Wasylishen RE, Gee M. Characterization of Tricoordinate Boron Chemical Shift Tensors: Definitive High-Field Solid-State NMR Evidence for Anisotropic Boron Shielding. J. Phys. Chem. A, 2001; 105(14): 3633-3640 
[46] Fujimoto H, Mabuchi A, Natarajan C, Kasuh T. Properties of graphite prepared from borondoped pitch as an anode for a rechargeable Li ion battery. Carbon, 2002; 40(4): 567-574

[47] Kane MS, Bushong JH, Foley HC, Brendley WH. Effect of Nanopore Size Distributions on Trichloroethylene Adsorption and Desorption on Carbogenic Adsorbents. Ind. Eng. Chem. Res. 1998; 37(6): 2416-2425

[48] Gogotsi Y, Portet C, Osswald S, Simmons JM, Yildirim T, Laudisio G, et al. Importance of Pore Size in High Pressure Hydrogen Storage by Porous Carbons, International Journal of Hydrogen Energy 2009; 34: 6314-6319

[49] Saha D, Contescu CI, Gallego NC. Tetrahydrofuran-induced K and Li doping onto poly(furfuryl alcohol)-derived activated carbon (PFAC): influence on microstructure and $\mathrm{H} 2$ sorption properties. Langmuir 2012; 28(13): 5669-77

[50] Dincă M, Dailly A, Liu Y, Brown CM, Neumann DA, Long JR. Hydrogen Storage in a Microporous Metal-Organic Framework with Exposed Mn2+ Coordination Sites. J. Am. Chem. Soc. 2006; 128 (51): 16876-16883

[51] Langmi HW, Rena J, North B, Mathe M, Bessarabov D. Hydrogen Storage in MetalOrganic Frameworks: A Review. Electrochimica Acta 2014, 128: 368-392

[52] Wang LF, Lachawiec AJ, Yang RT. Nanostructured Adsorbents for Hydrogen Storage at Ambient Temperature: High-Pressure Measurements and Factors Influencing Hydrogen Spillover. RSC Advances 2013; 3: 23935 